\title{
Análise de Risco Econômico de Dois Sistemas Produtivos de Carvão Vegetal
}

\author{
Aylson Costa Oliveira ${ }^{1}$, Bárbara Luísa Corradi Pereira ${ }^{1}$, Thiago Taglialegna Salles ${ }^{2}$, \\ Angélica de Cássia Oliveira Carneiro ${ }^{2}$, Artur Queiroz Lana ${ }^{3}$ \\ ${ }^{1}$ Departamento de Engenharia Florestal, Universidade Federal de Mato Grosso - UFMT, Cuiabá/MT, Brasil \\ ${ }^{2}$ Departamento de Engenharia Florestal, Universidade Federal de Viçosa - UFV, Viçosa/MG, Brasil \\ ${ }^{3}$ Escola Superior de Agricultura "Luiz de Queiroz" - ESALQ, Universidade de São Paulo - USP, Piracicaba/SP, Brasil
}

\section{RESUMO}

O objetivo deste trabalho foi analisar a viabilidade econômica da produção de carvão vegetal em sistema fornos-fornalha e fornos do tipo rabo-quente e realizar a simulação de risco de investimento. A análise econômica foi realizada pela determinação de Valor Presente Líquido (VPL), Valor Anual Equivalente (VAE) e Razão Benefício-Custo (B/C). A análise de risco foi realizada pelo método de Monte Carlo. O sistema fornos-fornalha apresentou maior viabilidade econômica. Os indicadores econômicos se mostraram viáveis e a análise de risco indicou probabilidade de os projetos serem inviáveis economicamente de $0,9 \%$ e $27,3 \%$ para o sistema fornos-fornalha e fornos rabo-quente, respectivamente. Conclui-se que a inclusão da análise de risco nas análises econômicas resulta em maior segurança para inferir sobre os indicadores econômicos.

Palavras-chave: fornos de alvenaria, valor presente líquido, simulação de Monte Carlo.

\section{Economic Risk Analysis of Two Systems of Charcoal Production}

\begin{abstract}
This study aimed to analyze the economic viability of charcoal production in kilns-furnace system and "rabo-quente" kilns, as well as the investment risk simulation. The economic analysis was performed by determining the following indicators: Net Present Value (NPV), Equivalent Annual Value (EAV) and Benefit - Cost Reason $(\mathrm{B} / \mathrm{C})$. The risk analysis was performed by the Monte Carlo method. Economic indicators were viable. Kilns-furnace system evidenced to be more viable economically. Risk analysis indicated that there is probability to economical unviability of evaluated systems, $0.9 \%$ and $27.3 \%$ for kilns-furnace system and "rabo-quente" kilns, respectively. Inclusion of risk analysis in economic analysis of charcoal production projects results in greater security to infer on economic indicators.
\end{abstract}

Keywords: kilns, net present value, Monte Carlo simulation. 


\section{INTRODUÇÃO}

O Brasil destaca-se mundialmente como o maior produtor e consumidor de carvão vegetal para fins industriais, com $84 \%$ da produção destinada às indústrias siderúrgicas de ferro-gusa e ferro-liga e o restante destinado ao uso doméstico e outras indústrias (EPE, 2015). Segundo dados da Associação Mineira de Silvicultura (AMS, 2014), no ano de 2013, o consumo de carvão vegetal no Brasil foi de 25,3 milhões de metros de carvão (mdc), sendo o Estado de Minas Gerais responsável por $80 \%$ dele. No mesmo ano, foram verificadas cerca de 48 mil pessoas empregadas direta e indiretamente no setor de produção e transporte de carvão vegetal em Minas Gerais, tanto na área rural quanto na urbana.

A produção de carvão vegetal é dependente da tecnologia de conversão, ou seja, do tipo de forno, além das características da madeira utilizada nas carbonizações e da mão de obra empregada. No que se refere à matéria-prima, diversas pesquisas envolvendo as propriedades da madeira vêm sendo realizadas com o intuito de promover a seleção de espécies do gênero Eucalyptus spp. destinadas à conversão energética (Neves et al., 2011; Santos et al., 2012; Pereira et al., 2013; Nones et al., 2015; Silva et al., 2015). Esses estudos visam à redução da variabilidade dessas propriedades, possibilitando aumento do rendimento gravimétrico em carvão vegetal e melhoria das propriedades do carvão.

Em relação à questão tecnológica de conversão da madeira em carvão vegetal, a produção brasileira ainda é em grande parte realizada em fornos rudimentares de alvenaria, com controle empírico da carbonização, resultando em baixo rendimento gravimétrico e impactos sociais, econômicos e ambientais. Segundo Carneiro et al. (2013), 70\%, da produção brasileira ocorre em fornos do tipo rabo-quente e fornos de superfície, utilizados por pequenos e médios produtores; $20 \% \mathrm{em}$ fornos retangulares, tecnologia utilizada pelas grandes empresas, e 10\% através de outras tecnologias.

Nos últimos anos, as empresas produtoras de carvão vegetal que fazem uso dos fornos retangulares têm adotado a queima dos gases da carbonização utilizando uma fornalha acoplada aos fornos, reduzindo assim as emissões de gases poluentes. Estudos recentes têm buscado a adoção e desenvolvimento de fornalhas para utilização em fornos utilizados pelos pequenos produtores de carvão vegetal, visando a melhoria das condições ambientais e de trabalho (Cardoso et al., 2010; Oliveira et al., 2013). Porém essas novas tecnologias apresentam custos mais elevados em relação às tecnologias tradicionais.

Segundo Guimarães et al. (2007), as análises financeira e econômica têm sua importância e interesse à medida que auxiliam na tomada de decisão do investimento, sendo imprescindíveis estudos nessa linha de conhecimento, principalmente para sistemas de produção que apresentem inovações tecnológicas. Além das questões técnicas e ambientais, a questão econômica deve ser considerada quando se deseja realizar o investimento em determinada tecnologia, devendo-se estabelecer qual opção disponível apresenta maior rentabilidade para o produtor. A análise econômica de um investimento envolve o uso de técnicas e critérios que comparam custos e receitas inerentes ao projeto, visando decidir se esse deve ou não ser implementado (Rezende \& Oliveira, 2008).

Os métodos tradicionais de avaliação econômica de projetos baseiam-se na análise de dados ou indicadores determinísticos. No entanto, as atividades florestais estão sujeitas a inúmeras incertezas e variações do mercado. De acordo com Coelho et al. (2008), para reduzir o risco na tomada de decisão, no que se refere à questão econômica, a técnica de Monte Carlo é uma ferramenta útil, ao permitir a observação do desempenho de uma variável de interesse em razão do comportamento de variáveis que encerram elementos de incerteza.

O método de Monte Carlo é uma técnica de amostragem artificial, empregada para operar numericamente sistemas complexos que tenham componentes aleatórios. Nesse método, são realizadas diversas simulações; em cada uma delas são gerados valores aleatórios para as variáveis de entrada sujeitos à incerteza, com distribuições determinadas previamente (Bruni et al., 1998). Ao final da simulação, são gerados uma gama de resultados possíveis com base nos valores aleatórios e as probabilidades de ocorrência desses resultados.

O objetivo deste trabalho foi analisar a viabilidade econômica da produção de carvão vegetal em duas tecnologias de conversão: fornos de superfície acoplados a fornalha para queima de gases (sistema fornos-fornalha) e fornos do tipo rabo-quente, sem sistema de queima de gases, assim como realizar a simulação de risco de investimento utilizando a técnica de Monte Carlo. 


\section{MATERIAL E MÉTODOS}

Para a realização das análises econômica e de risco de investimento da produção de carvão vegetal, definiu-se uma produção mensal média igual a 65,45 metros cúbicos de carvão (mdc), correspondendo a 785,4 mdc anuais, produção normal entre pequenos produtores de carvão vegetal.

As tecnologias de conversão utilizadas foram os sistemas fornos-fornalha e fornos rabo-quente, representados pelas Figuras $1 \mathrm{~A}$ e 1B, respectivamente.

O sistema fornos-fornalha é composto por quatro fornos circulares de superfície com capacidade de 12 estéreos (st) de madeira, acoplados através de dutos a uma fornalha para queima dos gases gerados na carbonização. Cada forno apresenta rendimento gravimétrico médio de $32 \%$ por carbonização e vida útil de 6 anos (Oliveira et al., 2013). Em relação aos fornos rabo-quente, foram considerados 5 fornos com capacidade de 12 st, não havendo para esses fornos nenhuma medida de controle das emissões. $\mathrm{O}$ rendimento gravimétrico médio de cada forno rabo-quente é igual a $25 \%$ e sua vida útil é de 2 anos (Carneiro et al., 2013).

O custo de construção do sistema fornos-fornalha com 4 fornos, incluindo dutos, fornalha e chaminé, para o Estado de Minas Gerais, foi igual a R\$ 4.390; enquanto os 5 fornos rabo-quente tiveram custo igual a R\$3.850 (Oliveira, 2012). O menor custo de construção dos fornos rabo-quente é consequência do menor número de tijolos utilizados na construção de cada forno, além de não haver nesse sistema construção de dutos, fornalha e chaminé.

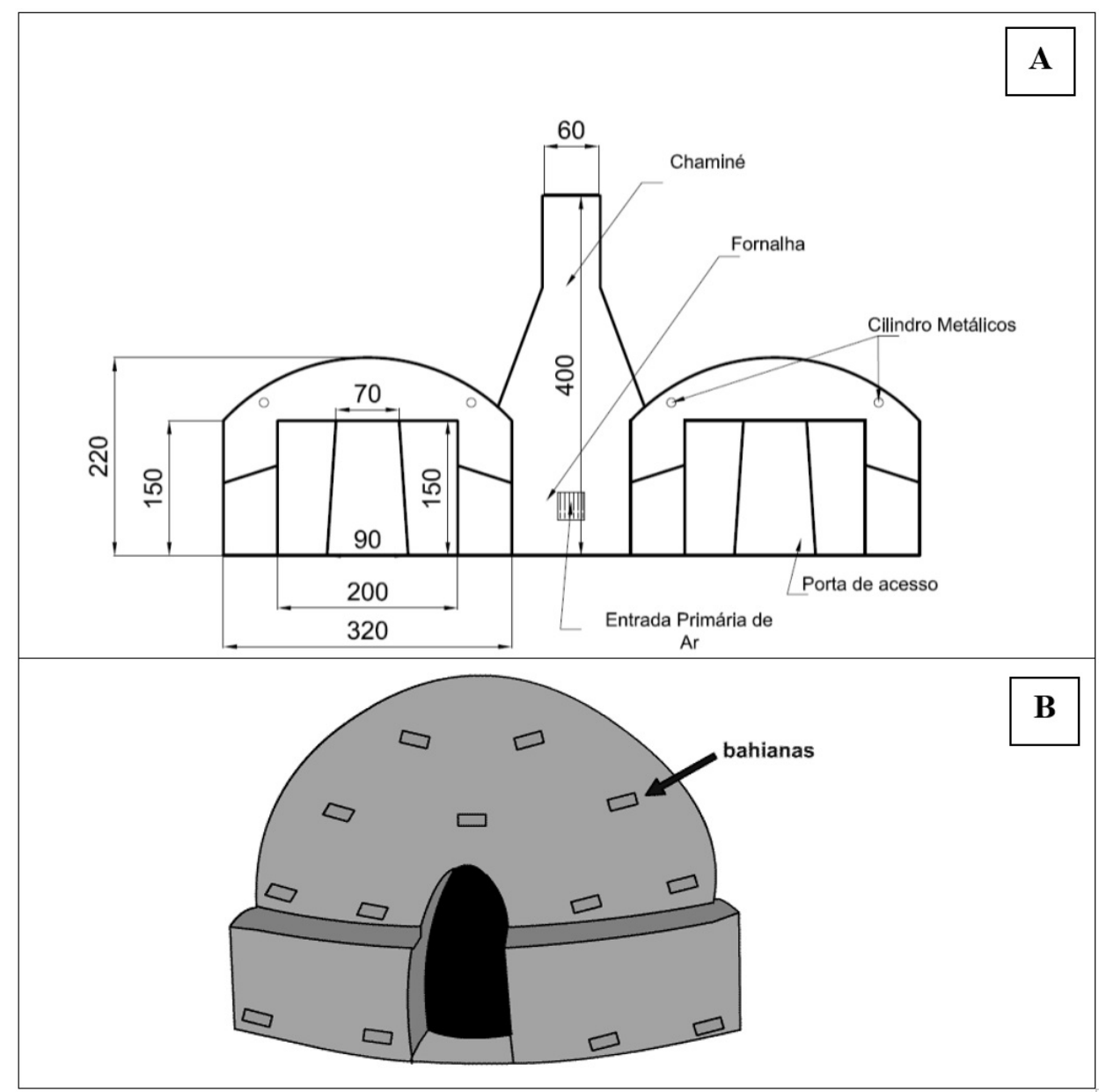

Figura 1. (A) Croqui ilustrativo do sistema forno-fornalha; (B) Esquema ilustrativo do forno rabo-quente. Figure 1. (A) Sketch illustration of kilns-furnace system; (B) Sketch illustration of "rabo-quente" kilns. 
Para a elaboração do fluxo de caixa de cada tecnologia de conversão, considerou-se $\mathrm{R} \$ 35,18$ como o custo do estéreo (st) de madeira de Eucalyptus ao longo de todo o horizonte de planejamento, e valor de venda do carvão vegetal igual a $\mathrm{R} \$ 110,00$ por mdc. Esses valores foram determinados de acordo com os valores médios verificados no Estado de Minas Gerais (CIFLORESTAS, 2015).

Nos anos em que não houve construção dos fornos, foi considerado um custo de manutenção igual a 5\% sobre o valor total gasto na sua construção, igual, portanto, a $\mathrm{R} \$ 219,50$ para o sistema fornos-fornalha e a $R \$ 192,50$ para os fornos rabo-quente.

\subsection{Análise econômica e financeira}

Foi considerado um horizonte de planejamento de 12 anos, contemplando 2 cortes de madeira de Eucalyptus aos 6 anos. A taxa de juros empregada foi 7,5\%. A análise econômica foi realizada através da determinação dos seguintes indicadores: Valor Presente Líquido (VPL), Valor Anual Equivalente (VAE) e Razão Benefício-Custo (B/C).

O VPL é definido como a diferença positiva entre receitas e custos, atualizados para uma determinada taxa de desconto (Equação 1). Para um projeto ser viável, o valor encontrado para esse critério deve ser maior que zero (Rezende \& Oliveira, 2008).

$$
\mathrm{VPL}=\sum_{j=0}^{n} R_{j}(1+i)^{-j}-\sum_{j=0}^{n} C_{j}(1+i)^{-j}
$$

em que: $R j=$ receitas no período $j ; C j=$ custos no período $j ; i=$ taxa de desconto; $j$ = período de ocorrência de $R j$ e $C j$; e $n=$ duração do projeto, em anos.

O VAE é uma parcela periódica e constante que paga o VPL da opção de investimento em análise ao longo do horizonte de planejamento. O VAE transforma o valor atual do projeto em um fluxo de receitas ou custos periódicos e contínuos. Valores positivos para esse critério indicam a viabilidade econômica do projeto avaliado, ou seja, quanto maior for o VAE, mais viável será o projeto (Rezende \& Oliveira, 2008). Com o período de capitalização anual, a fórmula de cálculo (Equação 2) é igual a:

$$
\mathrm{VAE}=\frac{V P L \times i}{\left[1-(1+i)^{-n}\right]}
$$

em que: $\mathrm{VPL}=$ valor presente líquido; $n=$ duração do projeto em anos; $i=$ taxa de desconto.
A razão benefício-custo (B/C) é obtida pela razão entre o valor presente dos benefícios e o valor presente dos custos para uma dada taxa de desconto (Equação 3). A viabilidade do projeto verifica-se quando o resultado é maior que 1 (Rezende \& Oliveira, 2008).

$\mathrm{B} / \mathrm{C}=\frac{\sum_{j=0}^{n} R_{j}(1+i)^{-j}}{\sum_{j=0}^{n} C_{j}(1+i)^{j}}$

em que: $R j=$ receita no final do ano $j$; $C j=$ custo no final do ano $j ; i=$ taxa de desconto; $n=$ duração do projeto, em anos.

Para a análise financeira, o indicador estimado foi a lucratividade. A lucratividade é um indicador que demonstra a eficiência operacional de um negócio. É expressa como um valor percentual que indica a proporção de ganhos de um negócio (Equação 4).

Lucratividade $=\frac{\text { Lucro Líquido }}{\text { Receita Total }} \times 100$

\subsection{Análise de risco}

A análise de risco de investimento foi realizada para o sistema fornos-fornalha e fornos rabo-quente. Para isso, os dados de custos e receitas foram analisados usando-se o software @RISK 6.0 (Palisade Corporation, 2012), desenvolvido para realizar simulações e que trabalha de maneira integrada à planilha Excel. Segundo Bentes-Gama et al. (2005), esse software permite a aplicação do método de Monte Carlo para simular valores para as variáveis aleatórias receita e custo e, em decorrência dos valores aleatórios gerados, obter valores para a variável lucro.

Foram definidas 10 mil interações. Para isso, foram consideradas como variáveis de entrada (inputs): Taxa de juros anual (\%); Custo de implantação do sistema fornos-fornalha e dos fornos rabo-quente (R\$); Rendimento gravimétrico de cada tipo de forno (\%); Custo da madeira (R\$/st); e Preço de venda do carvão vegetal $(\mathrm{R} \$ / \mathrm{mdc})$. Considerou-se variação entre $-20 \% a+20 \%$ para essas variáveis com base na distribuição triangular.

O indicador econômico Valor Presente Líquido (VPL) foi tomado como variável de saída (output).

\subsection{Custo de transporte do carvão vegetal}

Para a análise econômica dos dois sistemas produtivos de carvão vegetal, fornos rabo-quente e sistema fornos-fornalha, consideraram-se a produção 
de carvão e a sua comercialização na propriedade, sem considerar custos de transporte. Porém, em alguns casos, para comercializar o carvão vegetal produzido, o produtor necessita realizar o transporte, assumindo os custos decorrentes.

O custo de transporte por metro de carvão (mdc) foi calculado conforme a Equação 5, proposta por Rezende \& Oliveira (2008).

$$
\mathrm{C}=1,5 \cdot \mathrm{L}+(0,025 \cdot \mathrm{L}) \cdot \mathrm{D}
$$

em que: $C=$ custo de transporte $(\mathrm{R} \$ / \mathrm{mdc}) ; L=$ preço do litro de óleo diesel; $i=$ distância de transporte, em km.

Para cálculo do custo de transporte, considerou-se como $\mathrm{R} \$ 2,88$ o preço médio do litro de óleo diesel e $100 \mathrm{~km}$ como distância média de transporte, resultando em custo de transporte igual a $\mathrm{R} \$ 11,52 / \mathrm{mdc}$.

\section{RESULTADOS}

\subsection{Análise econômica e financeira}

Na Tabela 1 são apresentados os custos anuais atribuídos ao consumo da madeira e as receitas anuais geradas pela comercialização do carvão vegetal, no sistema fornos-fornalha e nos fornos rabo-quente.
Observa-se na Tabela 1 que para uma mesma produção de carvão vegetal e, portanto, uma mesma receita, os fornos rabo-quente apresentam custo com a madeira $25 \%$ maior que o sistema fornos-fornalha. Isso se deve à diferença no rendimento gravimétrico dos tipos de fornos analisados, $25 \%$ para o rabo-quente e $32 \%$ para o sistema fornos-fornalha. Tal fato acarreta em maior consumo de madeira e número de carbonizações anuais: 180 para os fornos rabo-quente contra 144 para o sistema fornos-fornalha.

O fluxo de caixa com os valores correntes (Tabela 2) foi elaborado de acordo com os custos e receitas determinados para a produção de carvão vegetal no sistema fornos-fornalha e nos fornos rabo-quente.

Observando-se os fluxos de caixa (Tabela 2), verifica-se que ambas as tecnologias de conversão da madeira em carvão apresentam saldo positivo a partir do primeiro ano. Além disso, observa-se que os fornos rabo-quente apresentam maior custo anual, provocado pelo maior consumo de madeira para produzir uma mesma quantidade de carvão vegetal que o sistema fornos-fornalha. Assim, o saldo total do sistema fornos-fornalha igual a $\mathrm{R} \$ 269.332,77$ é cerca de três vezes maior que o saldo dos fornos rabo-quente $(\mathrm{R} \$ 106.979,40)$.

Tabela 1. Custos anuais com madeira e receitas anuais do carvão vegetal.

Table 1. Annual costs with wood and annual revenues with charcoal.

\begin{tabular}{|lcccc|}
\multicolumn{1}{|c}{ Sistema de produção } & $\begin{array}{c}\text { Consumo de } \\
\text { madeira (st) }\end{array}$ & $\begin{array}{c}\text { Custo da madeira } \\
(\mathbf{R} \$)\end{array}$ & $\begin{array}{c}\text { Produção de } \\
\text { carvão (mdc) }\end{array}$ & $\begin{array}{c}\text { Receita do carvão } \\
\text { (R\$) }\end{array}$ \\
\hline Sistema fornos-fornalha & 1.728 & $60.791,00$ & 785,4 & $86.400,00$ \\
\hline Fornos rabo-quente & 2.160 & $75.988,80$ & 785,4 & $86.400,00$ \\
\hline
\end{tabular}

Tabela 2. Fluxo de caixa da produção de carvão vegetal.

Table 2. Cash flow of the charcoal production.

\begin{tabular}{|c|c|c|c|c|c|c|}
\hline \multirow{2}{*}{ Ano } & \multicolumn{3}{|c|}{ Sistema fornos-fornalha } & \multicolumn{3}{|c|}{ Fornos rabo-quente } \\
\hline & Custo & Receita & Saldo & Custo & Receita & Saldo \\
\hline 1 & $65.180,94$ & $86.400,00$ & $21.219,06$ & $78.838,80$ & $86.400,00$ & $7.561,20$ \\
\hline 2 & $61.010,54$ & $86.400,00$ & $25.389,47$ & $76.131,30$ & $86.400,00$ & $10.268,70$ \\
\hline 3 & $61.010,54$ & $86.400,00$ & $25.389,47$ & $78.838,80$ & $86.400,00$ & $7.561,20$ \\
\hline 4 & $61.010,54$ & $86.400,00$ & $25.389,47$ & $76.131,30$ & $86.400,00$ & $10.268,70$ \\
\hline 5 & $61.010,54$ & $86.400,00$ & $25.389,47$ & $78.838,80$ & $86.400,00$ & $7.561,20$ \\
\hline 6 & $61.010,54$ & $86.400,00$ & $25.389,47$ & $76.131,30$ & $86.400,00$ & $10.268,70$ \\
\hline 7 & $65.180,94$ & $86.400,00$ & $21.219,06$ & $78.838,80$ & $86.400,00$ & $7.561,20$ \\
\hline 8 & $61.010,54$ & $86.400,00$ & $25.389,47$ & $76.131,30$ & $86.400,00$ & $10.268,70$ \\
\hline 9 & $61.010,54$ & $86.400,00$ & $25.389,47$ & $78.838,80$ & $86.400,00$ & $7.561,20$ \\
\hline 10 & $61.010,54$ & $86.400,00$ & $25.389,47$ & $76.131,30$ & $86.400,00$ & $10.268,70$ \\
\hline 11 & $61.010,54$ & $86.400,00$ & $25.389,47$ & $78.838,80$ & $86.400,00$ & $7.561,20$ \\
\hline 12 & $61.010,54$ & $86.400,00$ & $25.389,47$ & $76.131,30$ & $86.400,00$ & $10.268,70$ \\
\hline Total & $740.467,23$ & $1.036 .800,00$ & $296.332,77$ & $929.820,60$ & $1.036 .800,00$ & $106.979,40$ \\
\hline
\end{tabular}


Conforme apresentado na Tabela 2, o sistema fornos-fornalha apresenta maiores custos nos anos 1 e 7 ( $\$$ \$ 65.180,94) em relação aos demais anos (R\$ 61.010,54) do horizonte de planejamento devido ànecessidade de reforma de toda a estrutura de produção de carvão, ou seja, devido à vida útil de 6 anos, nesses anos deve-se realizar a construção dos fornos, dutos, fornalha e chaminé. Nos demais anos, os custos do projeto são referentes aos custos com madeira e manutenção anual do sistema.

Os maiores custos $(\mathrm{R} \$ 78.838,80)$ nos anos ímpares para os fornos rabo-quente devem-se aos custos com madeira e construção dos fornos, que apresentam vida útil de 2 anos, devendo a reforma de toda a estrutura ocorrer em menor intervalo de tempo em comparação ao sistema fornos-fornalha. Nos demais anos, os custos referem-se ao consumo de madeira e manutenção dos fornos, totalizando $\mathrm{R} \$ 76.131,30$.

$\mathrm{Na}$ Tabela 3 são apresentados os indicadores econômicos, Valor Presente Líquido (VPL), Valor Anual Equivalente (VAE), Razão Benefício-Custo (B/C) e o indicador financeiro, Lucratividade para a produção de carvão vegetal no sistema fornos-fornalha e nos fornos rabo-quente.

O Valor Presente Líquido (VPL) foi positivo, indicando a viabilidade de ambos os projetos. Porém, o VPL obtido para o sistema fornos-fornalha foi igual a R\$ 190.001,40 e, para os fornos rabo-quente, de $\mathrm{R} \$ 68.581,13$. Assim, o lucro obtido com a produção e comercialização no projeto do sistema fornos-fornalha é cerca de três vezes maior que o lucro proporcionado pelos fornos rabo-quente.

O Valor Anual Equivalente (VAE) representa o lucro anual e foi positivo para os dois projetos analisados, indicando a viabilidade de ambos.

Tabela 3. Indicadores econômicos e financeiro da produção de carvão vegetal.

Table 3. Economic indicators and financial indicator of charcoal production.

\begin{tabular}{lcc}
\multicolumn{1}{c}{ Indicador } & $\begin{array}{c}\text { Sistema } \\
\text { fornos-fornalha }\end{array}$ & $\begin{array}{c}\text { Fornos } \\
\text { rabo-quente }\end{array}$ \\
\hline VPL (R\$) & $190.001,40$ & $68.581,13$ \\
VAE (R\$/ano) & $24.562,97$ & $8.866,02$ \\
B/C & 1,40 & 1,11 \\
\hline Lucratividade (\%) & 28,43 & 10,26 \\
\hline
\end{tabular}

O lucro anual do sistema fornos-fornalha foi de $\mathrm{R} \$ 24.562,97$, o que equivale a $\mathrm{R} \$ 2.046,92$ por mês. Vale ressaltar que não foi considerado o custo de transporte do carvão vegetal, nem o custo de mão de obra. Devido à pequena quantidade de fornos, o controle da carbonização é realizado pelo próprio produtor rural, logo esse valor representaria o pagamento mensal dos seus serviços. Segundo Minette et al. (2007), o pequeno produtor de carvão vegetal pode operar de 7 a 10 fornos, realizando todas as atividades envolvidas na carbonização da madeira.

Para os fornos rabo-quente, o lucro anual foi igual a $\mathrm{R} \$ 8.866,02$, com equivalente mensal de $\mathrm{R} \$ 738,84$, valor insuficiente para o pagamento dos serviços realizados pelo produtor rural, além de ser cerca de três vezes menor que o verificado para o outro sistema avaliado.

Normalmente, a escolha pelos fornos rabo-quente se deve à sua popularidade entre os pequenos produtores de carvão vegetal, que acreditam obter elevado lucro, pois não consideram o custo da madeira nem valor de remuneração digno para as atividades realizadas, apenas os custos com construção e manutenção dos fornos. Observa-se, em muitos casos, a utilização de madeira ilegal para a produção de carvão em fornos rabo-quente para obtenção de maior lucro por parte dos produtores, visto que a madeira ilegal, originadas de florestas nativas sem plano de manejo, apresenta custo inferior à dos plantios florestais de eucalipto.

Ambas as razões Benefício-Custo (B/C) foram superiores a 1. Para o sistema fornos-fornalha, a razão $\mathrm{B} / \mathrm{C}$ foi de 1,40 e, para os fornos rabo-quente, 1,11. Dessa forma, para o sistema fornos-fornalha, as receitas superaram os custos em $40 \%$, para os fornos rabo-quente, as receitas superaram em apenas $11 \%$ os custos envolvidos na produção de carvão vegetal.

Avaliando a produção de carvão vegetal em fornos rabo-quente, fornos retangulares e fornos metálicos, Silva et al. (2014) encontraram como valor da razão Benefício-Custo (B/C), valores iguais a 1,06; 1,15; e 1,20, respectivamente. Esses valores foram inferiores ao encontrado neste trabalho para o sistema fornos-fornalha. Para a produção em fornos rabo-quente, verificou-se 1,11 para as condições deste trabalho contra 1,06 no trabalho de Silva et al. (2014). Castro et al. (2007) encontrou relação Benefício-Custo igual a 1,13, no entanto esses autores não indicam o sistema utilizado para a conversão da madeira em carvão vegetal. 
A lucratividade do sistema fornos-fornalha foi de $28,43 \%$ ao ano, ou seja, para cada $\mathrm{R} \$ 100,00$ comercializados de carvão vegetal, o produtor terá como lucro $\mathrm{R} \$ 28,43$. Para os fornos rabo-quente, a lucratividade foi igual a $10,26 \%$, aproximadamente três vezes menor que a do sistema fornos-fornalha. Logo, realizando a produção e venda do carvão vegetal utilizando-se o sistema fornos-fornalha obtêm-se maior lucro.

Para o sistema fornos-fornalha, o preço máximo da madeira, para que o projeto seja viável economicamente, é $R \$ 49,39 /$ st, enquanto que o preço de comercialização do carvão vegetal não pode ser inferior a $\mathrm{R} \$ 78,73 / \mathrm{mdc}$. Já para os fornos rabo-quente, esse valor máximo do custo da madeira é de $\mathrm{R} \$ 39,28 /$ st e o preço mínimo do carvão igual a $\mathrm{R} \$ 98,71 /$ st. Observa-se que os valores de preço máximo da madeira e preço mínimo do carvão encontrados para os fornos rabo-quente foram próximos aos valores utilizados para a elaboração da análise econômica ( $\mathrm{R} \$ 35,18 /$ st para a madeira e R $\$ 110,00 / \mathrm{mdc})$. Portanto, se o custo da madeira aumentar e/ou o preço de venda do carvão diminuir, a utilização de fornos rabo-quente torna-se inviável.

Silva et al. (2014) observaram a viabilidade econômica avaliando a produção mensal de 956,23 toneladas de carvão vegetal em três sistemas produtivos: fornos rabo-quente, fornos retangulares e fornos metálicos. Porém, mesmo com maior custo de instalação, o sistema metálico apresentou maior viabilidade, devido ao menor consumo de madeira, visto seu melhor rendimento gravimétrico. Esse mesmo fato foi observado neste trabalho, o sistema fornos-fornalha, por apresentar menor consumo de madeira para uma mesma produção de carvão vegetal, tem os custos reduzidos e melhores indicadores econômicos.

Pelos resultados encontrados, o sistema fornos-fornalha apresentou maior viabilidade econômica, ou seja, gera maior lucro para uma produção anual média de 785,4 mdc nas condições apresentadas. Além disso, há também o ganho ambiental obtido pela mínima emissão de gases poluentes para a atmosfera, devido o acoplamento dos fornos a uma fornalha. A utilização de fornalha para a queima de gases gerados na carbonização resulta na redução de 96,95\% da emissão de metano $\left(\mathrm{CH}_{4}\right)$, 93,76\% de monóxido de carbono (CO) e 94,85\% da quantidade de material particulado, que são tóxicos ao ser humano e ao meio ambiente (Cardoso et al.,
2010). As emissões do sistema fornos-fornalha são compostas somente por calor, vapor de água e dióxido de carbono $\left(\mathrm{CO}_{2}\right)$.

\subsection{Análise de risco}

Mediante as simulações realizadas no software @Risk para o sistema fornos-fornalha e para os fornos"rabo-quente, elaborou-se a distribuição das probabilidades do indicador financeiro Valor Presente Líquido (VPL), conforme apresentado na Figura 2.

A distribuição da probabilidade dos valores do Valor Presente Líquido (VPL) para o sistema fornos-fornalha (Figura 2A) indicou que $5 \%$ dos valores obtidos pelas interações estão acima de $\mathrm{R} \$ 341.148,60$, com valor máximo igual a $R \$ 483.827,10$, enquanto outros $5 \%$ estão abaixo de $\mathrm{R} \$ 55.627,91$, com mínimo igual a R\$73.411,52. Mesmo o sistema fornos-fornalha apresentando elevada viabilidade econômica, a probabilidade do VPL assumir valor inferior a 0 , ou seja, do projeto tornar-se inviável economicamente, é igual a $0,9 \%$.

Para os fornos rabo-quente, a distribuição da probabilidade do VPL (Figura 2B) mostra que 5\% dos valores do VPL foram superiores a R $\$ 210.196,70$, alcançando máximo de $\mathrm{R} \$ 380.185,30$. Porém existe uma probabilidade de $27,3 \%$ de os valores de VPL, cujo mínimo foi igual a $\mathrm{R} \$ 245.735,00$, serem negativos. Isso aconteceria se o preço do carvão vegetal e o rendimento gravimétrico do forno estiverem em um nível inferior e os custos da madeira e de construção dos fornos estiverem elevados, tornando a produção de carvão vegetal em fornos rabo-quente inviável economicamente. De acordo com Coelho et al. (2008), a utilização da técnica de Monte Carlo proporciona maior grau de certeza na tomada de decisão, minimizando os riscos de decisões e investimentos.

A produção de carvão vegetal no sistema fornos-fornalha apresenta baixo risco de investimento $(0,9 \%)$, enquanto que para os fornos rabo-quente o risco é de 27,3\%. Segundo Castro et al. (2007), com a análise determinística não seria possível inferir sobre a possibilidade de esses projetos serem economicamente inviáveis, pois ela não trabalha com variáveis aleatórias e probabilísticas, como na simulação de Monte Carlo. Esses mesmos autores verificaram probabilidade igual a $12 \%$ de a produção de carvão vegetal, nas condições apresentadas por eles, tornar-se inviável economicamente. 

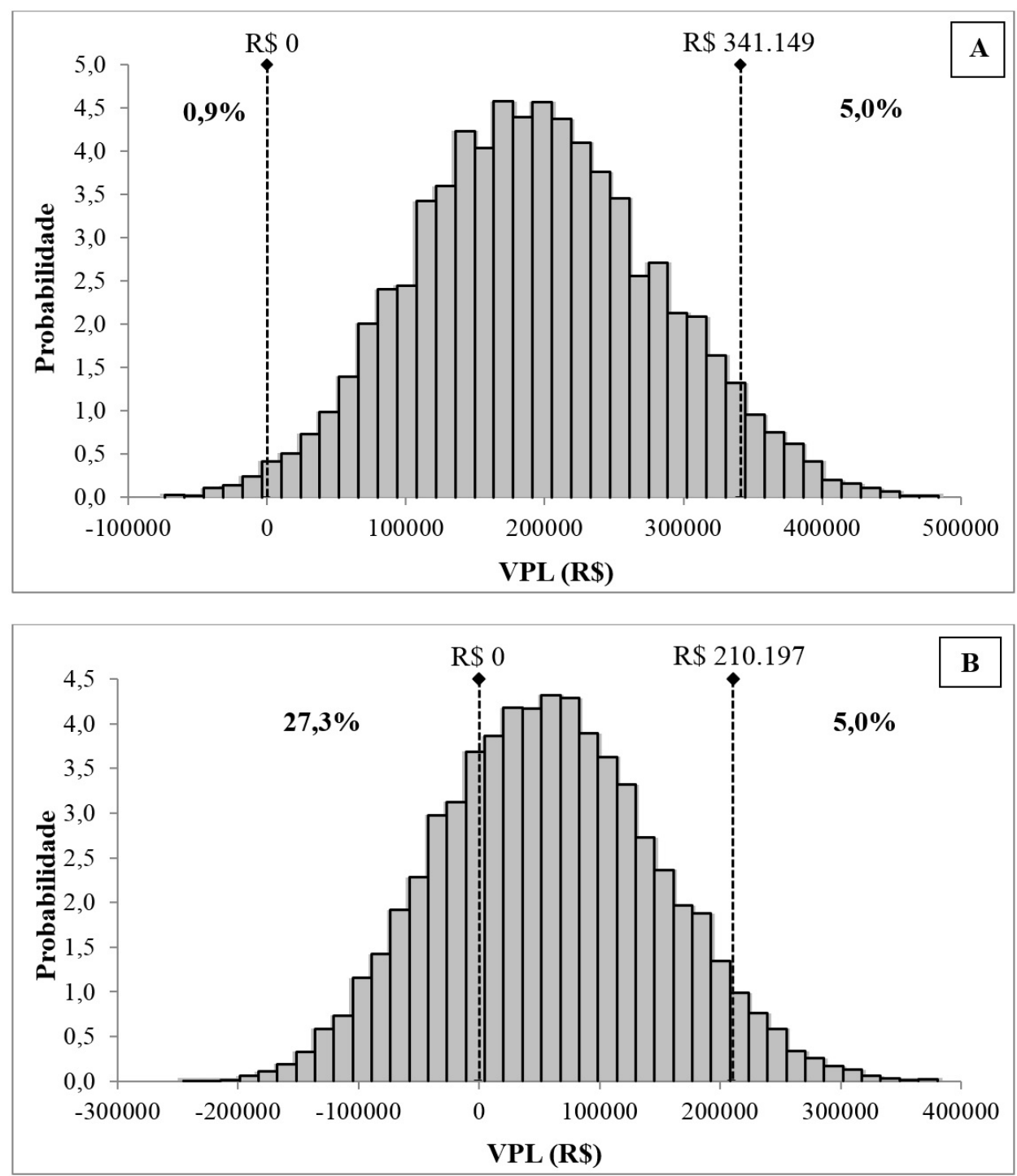

Figura 2. (A) Distribuição da probabilidade do VPL do sistema fornos-fornalha; (B) Distribuição da probabilidade do VPL dos fornos rabo-quente.

Figure 2. (A) Probability distribution of NPV of kilns-furnace system; (B) Distribution of probability of NPV of "rabo-quente" kilns.

Na Figura 3 são apresentados os resultados obtidos pela análise de sensibilidade para o sistema fornos-fornalha e para os fornos rabo-quente considerando: Rendimento gravimétrico (\%), Preço do carvão vegetal ( $\$$ /mdc), Custo da madeira (R\$/st), Taxa de juros (\% ao ano) e Custo de construção dos fornos (R\$) como variáveis de entrada (inputs) e o Valor Presente Líquido (VPL) como variável de saída (output).

De acordo com a análise de sensibilidade apresentada na Figura 3A, para o sistema fornos-fornalha, as variáveis que afetaram o VPL foram, em ordem de importância:
Rendimento gravimétrico (\%), Preço de venda do carvão vegetal ( $\mathrm{R} \$ / \mathrm{mdc})$, Custo da madeira ( $\mathrm{R} \$ \mathrm{st})$, Taxa de juros (\% ao ano) e Custo de implantação dos fornos $(\mathrm{R} \$)$.

As variáveis rendimento gravimétrico e preço do carvão influenciaram positivamente $\mathrm{o} \mathrm{VPL}$, enquanto as demais variáveis apresentaram influência negativa. Portanto, elevando-se em $10 \%$ os valores de rendimento gravimétrico e do preço do carvão, o VPL sofrerá um aumento de 6,2 e $6,1 \%$, respectivamente, e havendo a elevação de $10 \%$ dos valores de custo da madeira, 

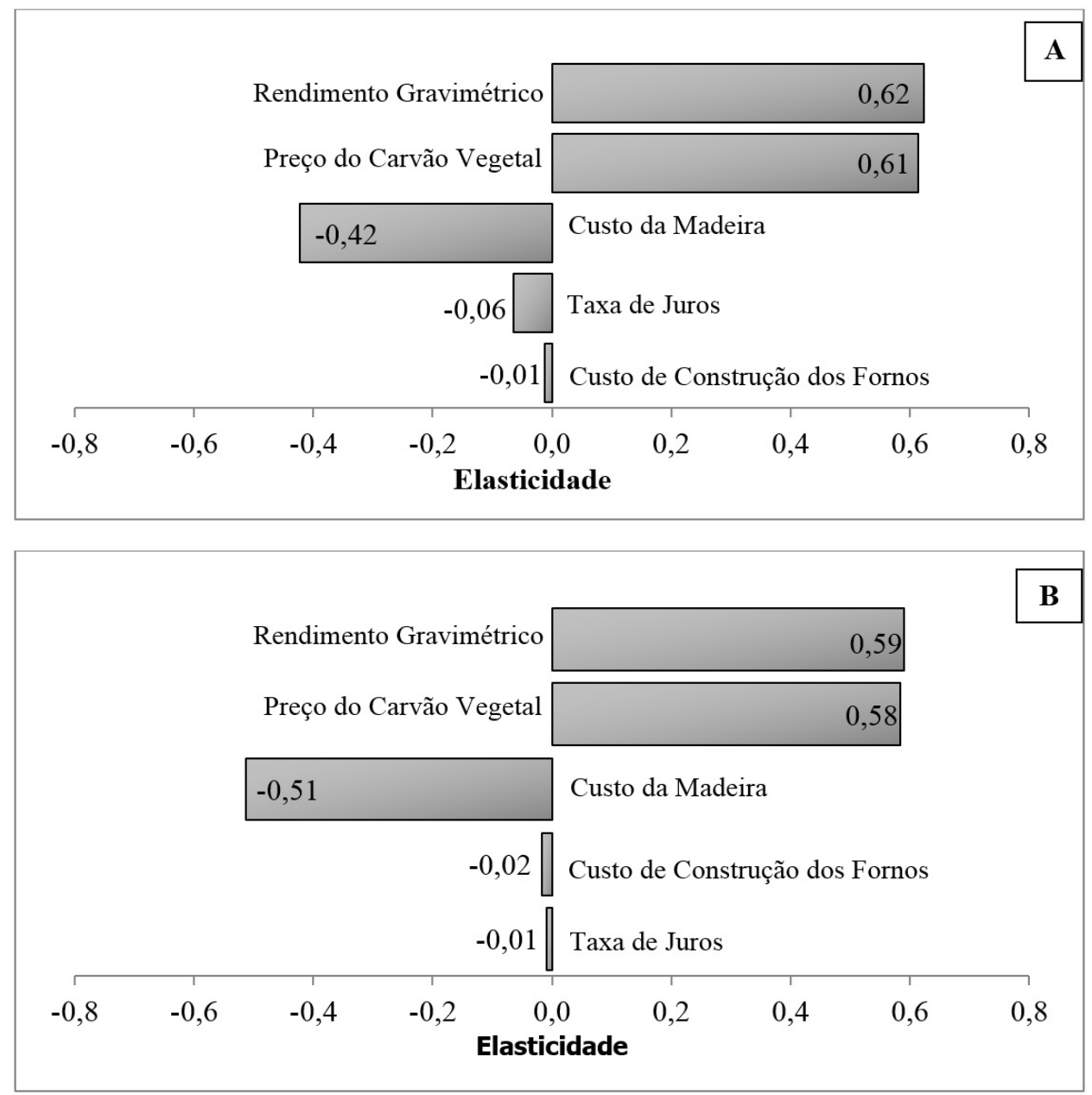

Figura 3. (A) Análise de sensibilidade das variáveis de entrada com a variável de saída (VPL) para o sistema fornos-fornalha; (B) Análise de sensibilidade das variáveis de entrada com a variável de saída (VPL) para os fornos rabo-quente.

Figure 3. (A) Sensitivity analysis of input variables and output variable (NPV) for the kilns-furnace system; (B) Sensitivity analysis of input variables and output variable (NPV) for the "rabo-quente" kilns.

taxa de juros e custo de construção de toda a estrutura de produção de carvão vegetal, o VPL terá redução respectivamente igual a $4,2 \%, 0,6 \%$ e $0,1 \%$.

Para os fornos rabo-quente, a análise de sensibilidade (Figura 3B) mostrou que as variáveis que mais afetam o VPL são: Rendimento gravimétrico (\%), Preço de venda do carvão vegetal ( $\mathrm{R} \$ \mathrm{mdc})$, Custo da madeira (R\$/st), Custo de implantação dos fornos (R\$) e Taxa de juros (\% ao ano). Portanto, esses fornos são menos sensíveis à taxa de juros que o sistema fornos-fornalha.

De acordo com essa análise, quando se elevam os valores de rendimento gravimétrico e do preço do carvão vegetal em $10 \%$ cada, provoca-se um aumento, respectivamente, de 5,9\% e de 5,8\% do VPL. As variáveis custo da madeira, custo de construção dos fornos e taxa de juros foram negativas, logo o aumento dessas variáveis reduz o valor do VPL. Elevando-se em 10\% essas variáveis, tem-se a redução do VPL igual a 5,1\%, $0,2 \%$ e $0,1 \%$, respectivamente.

Para ambas as tecnologias de conversão avaliadas verificou-se a maior sensibilidade do VPL para a variação dos valores de preço do carvão vegetal, rendimento gravimétrico e custo da madeira. Observou-se também que os fornos rabo-quente são mais sensíveis à variação do custo da madeira. Isso ocorre provavelmente por esse tipo de forno consumir maior quantidade de 
madeira durante o processo de carbonização. O custo de construção dos fornos e a taxa de juros tiveram influência insignificante sobre o VPL para ambos os tipos de forno. Castro et al. (2007), ao avaliarem a rentabilidade econômica e o risco na produção de carvão vegetal, verificaram que o VPL era bastante sensível ao preço de comercialização do carvão vegetal $(0,87)$ e menos sensível ao custo de implantação $(0,03)$.

\subsection{Custo de transporte do carvão vegetal}

Considerando-se a produção média anual de carvão vegetal de 785,4 mdc e custo do transporte igual a $\mathrm{R} \$ 11,52 / \mathrm{mdc}$, os custos anuais de produção de carvão nos fornos rabo-quente e no sistema fornos-fornalha tem um aumento de $\mathrm{R} \$ 9.047,81$, referentes ao transporte do carvão vegetal. $\mathrm{O}$ aumento dos custos reflete-se na redução dos valores verificados para os indicadores econômicos para o sistema fornos-fornalha e torna inviável a produção de carvão nos fornos rabo-quente nessas condições. Castro et al. (2007) verificaram que o custo de transporte afeta negativamente a rentabilidade da produção de carvão vegetal.

Considerando-se os custos com o transporte de carvão vegetal, para os fornos rabo-quente, os valores do VPL e VAE foram negativos, iguais, respectivamente, a $\mathrm{R} \$-1.407,67$ e $\mathrm{R} \$-181,98$, indicando inviabilidade econômica. A B/C reduziu-se de 1,11 para 1,00; e a lucratividade reduziu-se de 10,26\% para $-0,2 \%$.

Para a produção de carvão vegetal no sistema fornos-fornalha também houve redução dos valores dos indicadores econômicos, porém, a utilização desse sistema permaneceu viável economicamente. O VPL reduziu-se de R $\$ 190.001,40$ (Tabela 3) para R \$ 120.012,60, redução de 37\%. O VAE, considerando o transporte do carvão, reduziu-se para $\mathrm{R} \$ 15.514,97$, resultando em um valor mensal igual a $\mathrm{R} \$ 1.292,92$. $\mathrm{O}$ valor da $\mathrm{B} / \mathrm{C}$ de 1,40 reduziu-se para 1,22, permanecendo superior a 1 , indicando a viabilidade econômica; a lucratividade passou de $28,43 \%$, quando não se considerou o transporte, para $18 \%$ quando considerado o transporte. Ou seja, o produtor rural, de cada $R \$ 100,00$ de carvão vegetal comercializados, tem como lucro $\mathrm{R} \$ 18$ e não mais $\mathrm{R} \$ 28,43$.

Como o custo de transporte do carvão vegetal é influenciado pelo preço do óleo diesel e pela distância de transporte, se esses sofrerem redução, o custo de transporte será menor, melhorando os valores dos indicadores econômicos e a viabilidade econômica da produção de carvão vegetal nos dois sistemas produtivos avaliados. Outra forma de reduzir o custo de transporte por mdc de carvão seria a utilização de caminhões com maior capacidade de carga.

De acordo com Rezende \& Oliveira (2008), os preços verificados para o carvão vegetal são influenciados pelos custos de produção e pela distância entre a região produtora e o mercado consumidor. Esses autores, ao analisarem projetos de produção de carvão vegetal em Minas Gerais, em diferentes regiões produtoras e distâncias das indústrias consumidoras, verificaram que os projetos permaneciam viáveis economicamente com o transporte do carvão vegetal ocorrendo a uma distância de até $250 \mathrm{~km}$. Nas condições estabelecidas nesse trabalho, para os fornos rabo-quente, o raio máximo de transporte foi de $97 \mathrm{~km}$, enquanto que para o sistema fornos-fornalha a distância máxima de transporte seria de $374 \mathrm{~km}$. Ressalta-se, assim, que a unidade de produção de carvão vegetal que adotar esse sistema pode se situar a maior distância das indústrias consumidoras ou, também, buscar novos mercados.

\section{CONCLUSÃO}

Pode-se concluir que, nas condições apresentadas, o sistema fornos-fornalha apresenta maior viabilidade econômica que os fornos rabo-quente, gerando maior lucro para o produtor de carvão vegetal. Além dos ganhos financeiros, há o ganho técnico, devido ao maior rendimento gravimétrico, menor consumo de madeira e necessidade de menor número de fornos para uma mesma produção, e o ganho ambiental, devido ao fato de o sistema fornos-fornalha apresentar baixa emissão de poluentes durante a carbonização da madeira.

Pela análise de sensibilidade, as variáveis com maior influência sobre o VPL foram, de forma positiva, o preço do carvão vegetal e o rendimento gravimétrico e, de forma negativa, o custo da madeira.

Pela simulação de Monte Carlo existe a probabilidade de os projetos apresentarem valores negativos para o VPL, inviabilizando economicamente ambos os projetos. Porém a produção em fornos rabo-quente apresenta maior risco de tornar-se inviável, o que ocorre quando se considera na análise o transporte do carvão.

Conclui-se que a inclusão da análise de risco na análise econômica de projetos para a produção de carvão 
vegetal resulta em maior segurança para inferir sobre os indicadores econômicos e sua viabilidade econômica.

\section{STATUS DA SUBMISSÃO}

Recebido: 11 ago., 2016

Aceito: 1 out., 2016

\section{AUTOR(ES) PARA CORRESPONDÊNCIA}

\section{Aylson Costa Oliveira}

Departamento de Engenharia Florestal, Universidade Federal de Mato Grosso - UFMT, Av. Fernando Corrêa da Costa, 2367, Bairro Boa Esperança, CEP 78060-900, Cuiabá, MT, Brasil e-mail: aylsoncosta@gmail.com

\section{REFERENNCIAS}

Associação Mineira de Silvicultura - AMS. Anuário estatístico 2014: ano base 2013. Belo Horizonte, 2014.

Bentes-Gama MM, Silva ML, Vilcahuamán JM, Locatelli M. Análise econômica de sistemas agroflorestais na Amazônia Ocidental, Machadinho D'Oeste-RO. Revista Árvore 2005; 29(3): 401-411. http://dx.doi.org/10.1590/ S0100-67622005000300007.

Bruni AL, Famá R, Siqueira JO. Análise do risco na avaliação de projetos de investimento: uma aplicação de Monte Carlo. Caderno de Pesquisas em Administração 1998; 1(6): 62-75.

Cardoso MT, Damásio RAP, Carneiro ACO, Jacovine LAG, Vital BR, Barcellos DC. Construção de um sistema de queima de gases da carbonização para redução da emissão de poluentes. Cerne 2010; 16(Supl): 115-124.

Carneiro ACO, Vital BR, Oliveira AC, Pereira BLC. Pirólise lenta da madeira para produção de carvão vegetal. In: Santos F, Colodette J, Queiroz JH, organizadores. Bioenergia \& biorrefinaria: cana-de-açúcar \& espécies florestais. Visconde do Rio Branco: Suprema Gráfica e Editora; 2013.

Castro RR, Silva ML, Leite HG, Oliveira MLR. Rentabilidade econômica e risco na produção de carvão vegetal. Cerne 2007; 13(4): 353-359.

Centro de Inteligência em Florestas - CI Florestas. 2015. Cotações - carvão vegetal e eucalipto para carvão [online]. Viçosa: CI Florestas; 2005. [citado em 20 set. 2005]. Disponível em: http://www.ciflorestas.com.br

Coelho LM Jr, Rezende JLP, Oliveira AD, Coimbra LAB, Souza AN. Análise de investimento de um sistema agroflorestal sob situação de risco. Cerne 2008; 14(4): 368-378
Empresa de Pesquisa Energética - EPE. 2015. Balanço Energético Nacional 2015: Ano Base 2014. Rio de Janeiro: EPE; 2015. 266 p.

Guimarães RM No, Pimenta SA, Silva ML, Soares NS, Vital BR, Silva JC. Avaliação econômica e financeira de projetos de fornos dos tipos container industrial e retangular de 40 estéreos. Árvore 2007; 31 (4): 709-715.

Minette LJ, Pimenta AS, Faria MM, Souza AP, Silvia EP, Fiedler NC. Avaliação da carga de trabalho físico e análise biomecânica de trabalhadores da carbonização em fornos tipo "rabo-quente". Revista Árvore 2007; 31(5): 853-858. http://dx.doi.org/10.1590/S0100-67622007000500009.

Neves TA, Protássio TP, Couto AM, Trugilho PF, Silva VO, Vieira CMM. Avaliação de clones de Eucalyptus em diferentes locais visando à produção de carvão vegetal. Pesquisa Florestal Brasileira 2011; 31(68): 319-330. http:// dx.doi.org/10.4336/2011.pfb.31.68.319.

Nones DL, Brand MA, Cunha AB, Carvalho AF, Weise SMK. Determinação das propriedades energéticas da madeira e do carvão vegetal produzido a partir de Eucalyptus benthamii. Revista Floresta 2015; 45(1): 57-64.

Oliveira AC, Carneiro ACO, Pereira BLC, Vital BR, Carvalho AMML, Trugilho PF, Damásio RAP. Otimização da produção do carvão vegetal por meio do controle de temperaturas de carbonização. Revista Árvore 2013; 37(3): 557-566. http://dx.doi.org/10.1590/S0100-67622013000300019.

Oliveira AC. Sistema forno-fornalha para produção de carvão vegetal [dissertação]. Viçosa: Universidade Federal de Viçosa; 2012.

Palisade Corporation. Maker of risk and decisions analysis [online]. Canada: Palisade Corporation; 2012. [citado em 2015 ago. 17]. Disponível em: http://www.palisade.com

Pereira BLC, Carneiro ACO, Carvalho AMML, Trugilho PF, Melo ICNA, Oliveira AC. Estudo da degradação térmica da madeira de Eucalyptus através de termogravimetria e calorimetria. Revista Árvore 2013; 37(3): 567-576. http:// dx.doi.org/10.1590/S0100-67622013000300020.

Rezende JLP, Oliveira AD. Análise econômica e social de projetos florestais. 2. ed. Viçosa: Editora UFV; 2008. 386 p.

Santos RC, Carneiro ACO, Trugilho PF, Mendes LM, Carvalho AMML. Análise termogravimétrica em clones de eucalipto como subsídio para a produção de carvão vegetal. Cerne 2012; 18(1): 143-151. http://dx.doi.org/10.1590/ S0104-77602012000100017.

Silva DA, Muller B, Kuiaski EC, Eloy E, Behling A, Colaço CM. Propriedades da madeira de Eucalyptus benthamii para produção de energia. Pesquisa Florestal Brasileira 2015; 35(84): 481-485. http://dx.doi.org/10.4336/2015. pfb.35.84.677.

Silva DAL, Cardoso EAC, Varanda LD, Christoforo AL, Malinovski RA. Análise de viabilidade econômica de três sistemas produtivos de carvão vegetal por diferentes métodos. Revista Árvore 2014; 38(1): 185-193. http:// dx.doi.org/10.1590/S0100-67622014000100018. 